\title{
Adsorption of Rare Earth Elements (REEs) onto Activated Carbon Modified with Potassium Permanganate $\left(\mathrm{KMnO}_{4}\right)$
}

\author{
Naoki Kano ${ }^{1, *}$, Meiling Pang ${ }^{2}$, Yanling Deng ${ }^{2}$ and Hiroshi Imaizumi ${ }^{1}$ \\ ${ }^{1}$ Department of Chemistry and Chemical Engineering, Faculty of Engineering, Niigata University, Niigata \\ 950-2181, Japan \\ ${ }^{2}$ Graduate School of Science and Technology, Niigata University, Niigata 950-2181, Japan
}

\begin{abstract}
The adsorption capacity of activated carbon modified with potassium permanganate $\left(\mathrm{KMnO}_{4}\right)$ for rare earth elements (REEs) from aqueous solution was investigated. The modified activated carbon was characterized by SEM (scanning electron microscopy), FT-IR (Fourier transform infrared spectrometer), and $\mathrm{N}_{2}$ adsorption-desorption tests. Adsorption experiments from aqueous solutions containing known amounts of some REEs (i.e. La, Lu, Yb, Eu, Y, Sc) onto the carbon were explored in a batch system. The amount of REEs adsorbed at different pH values, initial concentrations, and contact times were determined by inductively coupled plasma-atomic emission spectrometry (ICP$A E S$ ) in order to determine the optimum conditions for REEs adsorption. The adsorption of REEs on the activated carbon was well fitted by the Langmuir isothermal adsorption equation. The rates of adsorption were found to conform to pseudo-second order kinetic. These results present the modified activated carbon as an efficient adsorbent for REEs, hence creating new avenues for the treatment of industrial waste waters including pollutants. It is very significant information from the viewpoint of environmental protection.
\end{abstract}

Keyword: Adsorption, modified activated carbon, rare earth elements (REEs), adsorption isotherms, kinetics.

\section{INTRODUCTION}

Environmental pollution became a popular issue in the world with the rapid development of modern industry and agriculture [1, 2]. In particular, water pollution due to heavy metal has become one of the largest problems in recent years [3,4]. On the other hand, the demand of rare earth elements (REEs) in modern technology has increased remarkably over the past years [5, 6]. However, the shortage of trace metals including REEs (and the necessity of stable supply for these metals) has been concerned in recent years. Therefore, the development of the removal (or recovery) method for the trace metals is important from the viewpoint of resources recovery as well as environmental protection.

In recent decades, geochemical processes controlling metal migration and deposition in the earth's surface environment has been intensively and increasingly attracting much interest of scientists [7-9]. Rare earth is used in many industrial activities including mining and refining, which can cause environmental consequences if not properly managed. Therefore, it is significant to remove (or recover) metallic elements within the scope of permissible concentration before discharging into subsurface environments. Considering the technical, economical and health-related points, the

${ }^{*}$ Correspondence Address to this author at the Department of Chemistry and Chemical Engineering, Faculty of Engineering, Niigata University, Niigata 9502181, Japan; Tel: +81-25-262-7218; Fax: +81-25-262-7218

E-mail: kano@eng.niigata-u.ac.jp adsorption process seems to be a more appropriate technology for the removal (and/or recovery) of REEs from pollutants $[10,11]$.

There are many conventional methods for the removal of heavy metals from wastewater. These methods include chemical precipitation, ion-exchange, evaporation, reverse osmosis, membrane filtration, and adsorption [12]. Among them, adsorption is proven to be economical and effective method for the removal of a number of contaminates from water $[13,14]$.

Activated carbon (AC) has shown great potential for the removal of various inorganic, organic pollutants and radionuclides due to properties such as large surface area, microporous structure and high adsorption capacity. Powdered activated charcoal, which is one of the representative paradigms among nanostructured carbon materials, continues to attract tremendous attention in the past two decades due to their unique physical and chemical properties [15, 16]. In particular, chemical functionalization of AC can modify their physical and chemical properties, leading to the improvement of their performance for specific applications [17-19].

The modification of AC is known to play a key role in enhancing the adsorption efficiency because of the change in the surface morphology and the function by particular functional groups $[17,20,21]$. The employed adsorbent can be regenerated by suitable desorption process $[22,23]$. 
It is known that potassium permanganate $\left(\mathrm{KMnO}_{4}\right)$ can be a powerful oxidizing agent, and used for the improvement of the capabilities in ACs [24-26]. The physicochemical properties of AC may be improved after oxidation, which made ACs possess not only a more hydrophilic functional groups (e.g. $-\mathrm{COOH}$ ) but also more negatively charged surface $[27,28]$.

Then, $\mathrm{KMnO}_{4}$ was selected as oxidizing agent for the modification of $A C$ in this work.

The modification of AC, which provides ACs comparable performance for its water purification capabilities, is gaining prominence in a range of applications. It is an established fact that the $A C$ surface can display acidic, basic and/or neutral characteristics depending on the presence of surface functional groups [29].

Considering the above-mentioned, the uptake experiments for the adsorption of REEs from aqueous solution by $\mathrm{AC}$ modified with $\mathrm{KMnO}_{4}$ was carried out in this work. Two kinds of the concentrations of $\mathrm{KMnO}_{4}$ $(0.01 \mathrm{~mol} / \mathrm{L}$ and $0.03 \mathrm{~mol} / \mathrm{L})$ were used to investigate the efficiency of activated carbon as adsorbent for REEs for more practical use in future. Furthermore, to evaluate the characteristics of $\mathrm{AC}$ modified with $\mathrm{KMnO}_{4}$ in this work, the surface morphology, the specific surface area and the functional group of the material were determined by SEM (Scanning Electron Microscope), BET (Brunaeur, Emmet and Teller) method, and FT-IR respectively.

\section{EXPERIMENTAL SECTIONS}

\subsection{Materials}

Activated carbon used in the study was purchased from the Sigma-Aldrich, Inc., USA. This product is untreated and granular with a particle size of less than 75 microns (100-400 mesh). The carbon is prepared from wood which has been chemically activated. Chemical reagents including $\mathrm{KMnO}_{4}$ were purchased from Kanto Chemical Co., Inc. (Japan). For all experiments, each stock solution was suitably diluted with deionized water for use. All reagents used were of analytical grade, and water ( $>18.2 \mathrm{M} \Omega$ ) which was treated by an ultrapure water system (Advantec aquarius: RFU 424TA) was employed throughout the work.

\subsection{Apparatus}

The concentration of REEs was determined by ICPAES (inductively coupled plasma-atomic emission spectrometry, SEIKO SPS1500). The modified activated carbon was characterized using FT-IR (Fourier transform infrared spectroscopy, FTIR-4200, Jasco, Japan) in pressed $\mathrm{KBr}$ pellets, SEM (scanning electron microscopy, JCM-6000, JEOL) and $\mathrm{N}_{2}$ adsorption/desorption tests (Micromeritics TriStar 3020). The measurement of $\mathrm{pH}$ in solution was carried out using a $\mathrm{pH}$ meter (HORIBA, F-21, Japan).

\subsection{Modification of Activated Carbon Modified with Potassium Permanganate}

The $A C$ was washed with deionized water $\left(\right.$ at $80^{\circ} \mathrm{C}$ ) to remove fine powder and contaminants, then dried at $110^{\circ} \mathrm{C}$ for $2 \mathrm{~h}$ before use. $5 \mathrm{~g}$ of the activated carbon were placed in a $200 \mathrm{~mL}$ conical flask containing $50 \mathrm{~mL}$ $\mathrm{KMnO}_{4}$ solution $(0.01$ or $0.03 \mathrm{~mol} / \mathrm{L})$. Adjusting the temperature to $25^{\circ} \mathrm{C}$ and stirring for $12 \mathrm{~h}$, the resulting solution was filtrated through $0.45 \mu \mathrm{m}$ membrane filter. Then, the carbon was washed with deionized water until the $\mathrm{pH}$ (of the filtrate) is constant. The activated carbon was dried at $70{ }^{\circ} \mathrm{C}$ for $6 \mathrm{~h}$. The pristine and modified (i.e. modified with $0.01 \mathrm{~mol} / \mathrm{L}$ and $0.03 \mathrm{~mol} / \mathrm{L}$ $\mathrm{KMnO}_{4}$ solution) activated carbons were described as $A C_{0}, A_{K_{1} 1}$ and $A C_{K 3}$, respectively as below.

\subsection{Adsorption Experiments}

For investigating the effects of $\mathrm{pH}$, contact time, sorbent dose and initial concentration on the adsorption of REEs, the following adsorption experiments were performed using $A C_{0}, \quad A C_{K 1}$ and $A_{C_{K} 3}$. Activated carbons were thoroughly mixed into the solution (50 $\mathrm{mL}$ ) containing known amount of REEs in a $200 \mathrm{~mL}$ conical flask, and the suspensions were shaken in a water bath at room temperature $\left(25 \pm 2{ }^{\circ} \mathrm{C}\right)$. Adsorption experiments were conducted in the $\mathrm{pH}$ range of $2-8$, adsorbent dosage of $50 \mathrm{mg}$, contact time from $30 \mathrm{~min}$ to $12 \mathrm{~h}$, and initial concentration of $100 \mu \mathrm{g} \cdot \mathrm{L}^{-1}$. The $\mathrm{pH}$ of each solution was adjusted by using $0.1 \mathrm{~mol} \cdot \mathrm{L}^{-1} \mathrm{NaOH}$ and $0.1 \mathrm{~mol} \cdot \mathrm{L}^{-1} \mathrm{HNO}_{3}$.

Adsorption isotherms of REEs onto carbons were measured at varying initial REEs concentrations under optimized conditions.

Following each adsorption experiment, the suspension containing carbon and the above standard solution was filtered through a $0.45 \mu \mathrm{m}$ membrane filter (Advantec Mixed Cellulose Ester, $47 \mathrm{~mm}$ ) to remove REEs that have been adsorbed into the carbon, and the concentration of REEs in the filtrate was determined with an ICP-AES. 
The metal uptake by the carbons was calculated using the following equation:

$q=\frac{\left(C_{i}-C_{e}\right)}{m} \cdot V$

where $q$ is the adsorption capacities of REEs using unmodified and modified activated carbon at equilibrium $\left(\mathrm{mg} \cdot \mathrm{g}^{-1}\right), C_{i}$ and $C_{e}$ are the initial and equilibrium concentrations of metal ions in a batch system respectively $\left(\mathrm{mg} \cdot \mathrm{L}^{-1}\right), V$ is the volume of the solution $(\mathrm{L})$, and $\mathrm{m}$ is the weight of adsorbent $(\mathrm{g})$.

\subsection{Adsorption Isotherms}

Adsorption is usually described through isotherms, that is, the amount of adsorbate on the adsorbent as a function of concentration at constant temperature. The quantity adsorbed is usually normalized by the mass of the adsorbent to allow the comparison of different materials [30-32]. Two common adsorption model, Langmuir and Freundlich isotherm model was applied to evaluate the adsorption data obtained in this study.

Langmuir model assumes monolayer sorption onto a surface and is given by

$$
\frac{C_{e}}{q_{e}}=\frac{C_{e}}{q_{\max }}+\frac{1}{K_{L} q_{\max }}
$$

where $C_{e}$ is the concentration of REEs in a batch system at equilibrium $\left(\mathrm{mg} \cdot \mathrm{L}^{-1}\right), q_{e}$ is the amount of adsorption of REEs at equilibrium $\left(\mathrm{mg} \cdot \mathrm{g}^{-1}\right), q_{\max }$ is the maximum adsorption capacity on the surface of activated carbon $\left(\mathrm{mg} \cdot \mathrm{g}^{-1}\right), K_{L}$ is the equilibrium adsorption constant $\left(\mathrm{L} \cdot \mathrm{mg}^{-1}\right)$. A plot of $C_{e} / q_{e}$ versus $C_{e}$ gives a straight line with slope of $1 / q_{\max }$, and intercept is $1 /\left(K_{L} q_{\max }\right), K_{L}$ can be related to the adsorption free energy $\Delta G_{\text {ads }}\left(\mathrm{J} \cdot \mathrm{mol}^{-1}\right)$, by the following equation:

$n \Delta G_{\text {ads }}=-R T \ln K_{L}$

where $R$ is the gas constant $\left(8.314 \mathrm{~J} \cdot \mathrm{K}^{-1} \mathrm{~mol}^{-1}\right), T$ is the absolute temperature at equilibrium $(K)$, and $K_{L}$ is the equilibrium constant at temperature $T$.

The equilibrium constant, $b$ can be calculated from:

$K_{L}=q_{\mathrm{e}} / C_{e}$

where $C_{\mathrm{e}}$ and $q_{\mathrm{e}}$ were same as mentioned above in Eq. (2).

The equilibrium adsorption constant $[33,34]\left(K_{L}\right)$ can be used to determine the suitability of the adsorbent to adsorbate by using dimensionless parameter, Hall separation factor [35] $\left(R_{L}\right)$, which is defined as:

$R_{L}=\left(\frac{1}{1+K_{L} C_{0}}\right)$

where $C_{0}\left(\mathrm{mg} \cdot \mathrm{L}^{-1}\right)$ is the initial concentration.

The linearized Freundlich model isotherm is represented by the following equation:

$\log _{10} q_{e}=\log _{10} K_{F}+(1 / n) \log _{10} C_{e}$

The plots of $q_{\mathrm{e}} v s . C_{e}$ in log scale can be plotted to determine values of $1 / n$ and $K_{F}$ from power equation depicting the constants of Freundlich model.

\subsection{Kinetic Studies}

Kinetic models have been proposed to determine the mechanism of the adsorption process which provides useful data to improve the efficiency of the adsorption and feasibility of process scale-up [36, 37]. In the present investigation, the mechanism of the adsorption process was studied by fitting pseudo firstorder and second-order reactions to the experimental data.

The pseudo first-order model is given by the following equation:

$\ln \left(q_{e}-q_{t}\right)=\ln \left(q_{e}\right)-k_{1} t$

where $q_{e}$ and $q_{t}$ are the adsorption capacities of REEs using carbon at equilibrium and time $t$, respectively $\left(\mathrm{mol} \cdot \mathrm{g}^{-1}\right)$, and $k_{1}$ is the rate constant of the pseudo-firstorder adsorption $\left(\mathrm{h}^{-1}\right)$.

The linear form of the pseudo second-order rate equation is given as follows:

$\frac{t}{q_{t}}=\frac{1}{k q_{e}^{2}}+\frac{t}{q_{e}}$

where $q_{e}$ and $q_{t}$ are the adsorption capacities of REEs using carbon at equilibrium and time $t$, respectively $\left(\mathrm{mol} \cdot \mathrm{g}^{-1}\right)$, and $k$ is the rate constant of the pseudosecond-order adsorption $\left(\mathrm{g} \cdot \mathrm{mol}^{-1} \cdot \mathrm{h}^{-1}\right)$.

\section{RESULTS AND DISCUSSION}

\subsection{Characteristics of Modified Activated Carbon}

The FT-IR spectra of the pristine and modified activated carbons (i.e. $A C_{0}, A C_{K 1}$ and $A C_{K 3}$ ) are shown 
in Figure 1. The carbons displayed the characteristic bands of the graphite structure of carbon at $1615 \mathrm{~cm}^{-1}$. Hydroxyl groups (-OH) stretching band, which is one of the typical peaks of activated carbon, was found at 3300 to $3500 \mathrm{~cm}^{-1}$. The peak at $3433 \mathrm{~cm}^{-1}$ may be related to the $-\mathrm{OH}$ stretch from deprotonated pristine and modified AC. The wide peak at 1550 to $1750 \mathrm{~cm}^{-1}$ shows the asymmetric stretch of the carboxylate group $(-\mathrm{COOH})$. These peaks are generally in good agreement with those in other previous works $[21,38$, 39].

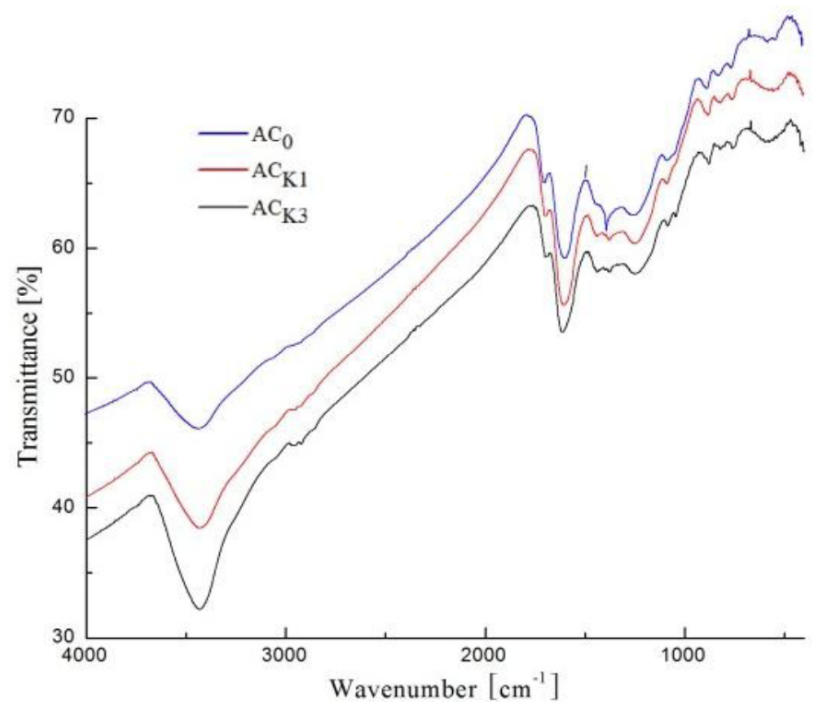

Figure 1: $F T-I R$ spectra of $A C_{0}, A C_{K 1}$, and $A C_{K 3}$.

The surface properties of the ACs were investigated by $\mathrm{N}_{2}$ adsorption (TriStar II 3020 Micromeritics), and the analytical results for the adsorption/desorption isotherms are shown in Table 1.

The pore volume was calculated from the amount of $\mathrm{N}_{2}$ adsorbed at the relative pressure of 0.99 . The pore size was calculated from the adsorption average pore width (4V/A by BET) in this work. From Table 1, it is found that the pore volume and pore size decreased significantly after modification with $\mathrm{KMnO}_{4}$. The isotherm showed a type $\mathrm{H} 1$ isotherm with a clear hysteretic loop, which is characteristic of disordered micro-porous materials.
The SEM micrographs of the ACs are shown in Figure 2. The modified AC (Figure 2B and 2C) seemed to exhibit a more compact stacking morphology than the pristine AC (Figure 2A), due to cohesive forces, which may be generated from the introduction of oxygen containing functional groups. These results are consistent with those of $\mathrm{N}_{2}$ adsorption-desorption experiment. The decrease of the pore volume and pore size may be related to the increase of acidic groups on the surface of activated carbon treated with $\mathrm{KMnO}_{4}$.

\subsection{Effect of pH}

Aqueous solution $\mathrm{pH}$ can affect the surface charge of the adsorbent, the degree of ionization and speciation of metal ions and surface metal binding sites $[40,41]$. The effect of initial $\mathrm{pH}$ on the adsorption of REEs on ACs was investigated over a $\mathrm{pH}$ range 2-6 under the initial concentrations of $100 \mu \mathrm{g} \cdot \mathrm{L}^{-1}$, and the results are shown in Figure 3. During the experiment, the $\mathrm{pH}$ range was kept below 7.0 in order to avoid any bulk precipitation of REE hydroxides. The adsorption capacity of each REEs on ACs reached maximum at $\mathrm{pH} 3$, and more than $80 \%$ was observed at $\mathrm{pH} 3$ in case of $\mathrm{AC}_{\mathrm{K} 3}$ than $\mathrm{AC}_{0}$.

This $\mathrm{pH}$ dependency can be described by considering a decrease in the positive surface charges at aqueous solution $\mathrm{pH}[42,43]$. Then, $\mathrm{pH} 3$ was selected as the optimal $\mathrm{pH}$ for further work.

\subsection{Effect of Contact Time}

In order to optimize the contact time required for achievement to equilibrium, adsorption experiments of REEs (initial concentration $100 \mu \mathrm{g} \cdot \mathrm{L}^{-1}$ ) from aqueous solutions were performed for $30 \mathrm{~min}$ to $12 \mathrm{~h}$ by using $50 \mathrm{mg}$ of $\mathrm{ACs}$ at $\mathrm{pH} \mathrm{3}$. The representative result is shown in Figure $\mathbf{4}$ for the case of Sc. It indicates that a relatively fast adsorption of REEs occurred onto $A C_{K 1}$ and $\mathrm{AC}_{\mathrm{K} 3}$ than onto $\mathrm{AC}_{0}$.

Hence, the optimized contact time was taken $8 \mathrm{~h}$ for the rest of the experimental work.

Table 1: Textural Characteristics of Activated Carbon

\begin{tabular}{|c|c|c|c|}
\hline Adsorbent & $\begin{array}{c}\text { BET surface area } \\
{\left[\mathbf{m}^{2} \cdot \mathbf{g}^{-1}\right]}\end{array}$ & $\begin{array}{c}\text { Pore volume } \\
{\left[\mathbf{c m}^{3} \cdot \mathbf{g}^{-1}\right]}\end{array}$ & $\begin{array}{c}\text { Pore size } \\
{[\mathbf{n m}]}\end{array}$ \\
\hline \hline $\mathrm{AC}_{0}$ & 381 & 0.402 & 4.23 \\
\hline $\mathrm{AC}_{\mathrm{k} 1}$ & 373 & 0.390 & 4.18 \\
\hline $\mathrm{AC}_{\mathrm{k} 3}$ & 346 & 0.348 & 4.03 \\
\hline
\end{tabular}



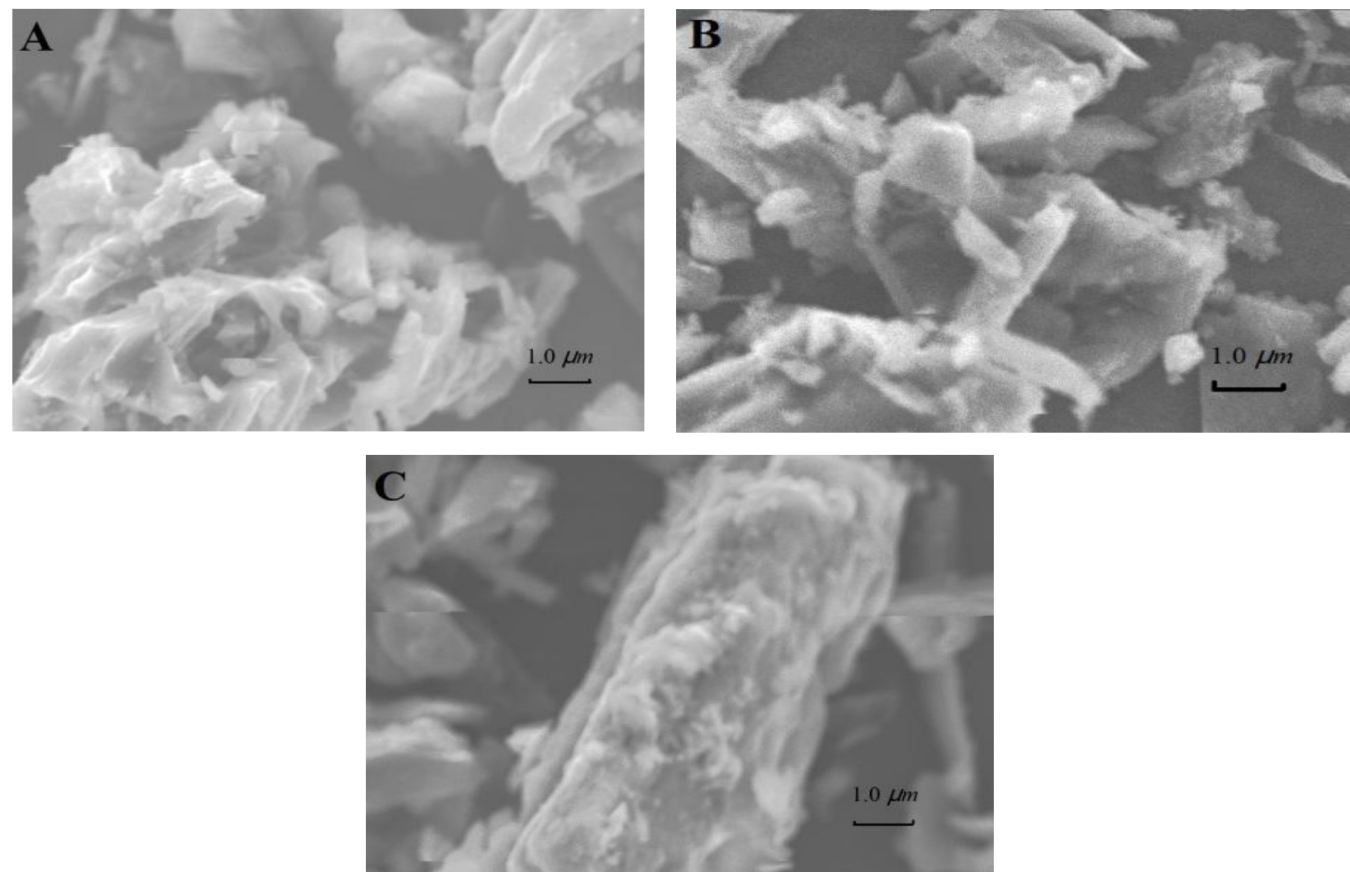

Figure 2: SEM micrographs of the surface of activated carbon: (A) unmodified; (B) modified with 0.01 mol/L $\mathrm{KMnO}_{4} ;(\mathbf{C})$ modified with $0.03 \mathrm{~mol} / \mathrm{L} \mathrm{KMnO}_{4}$.
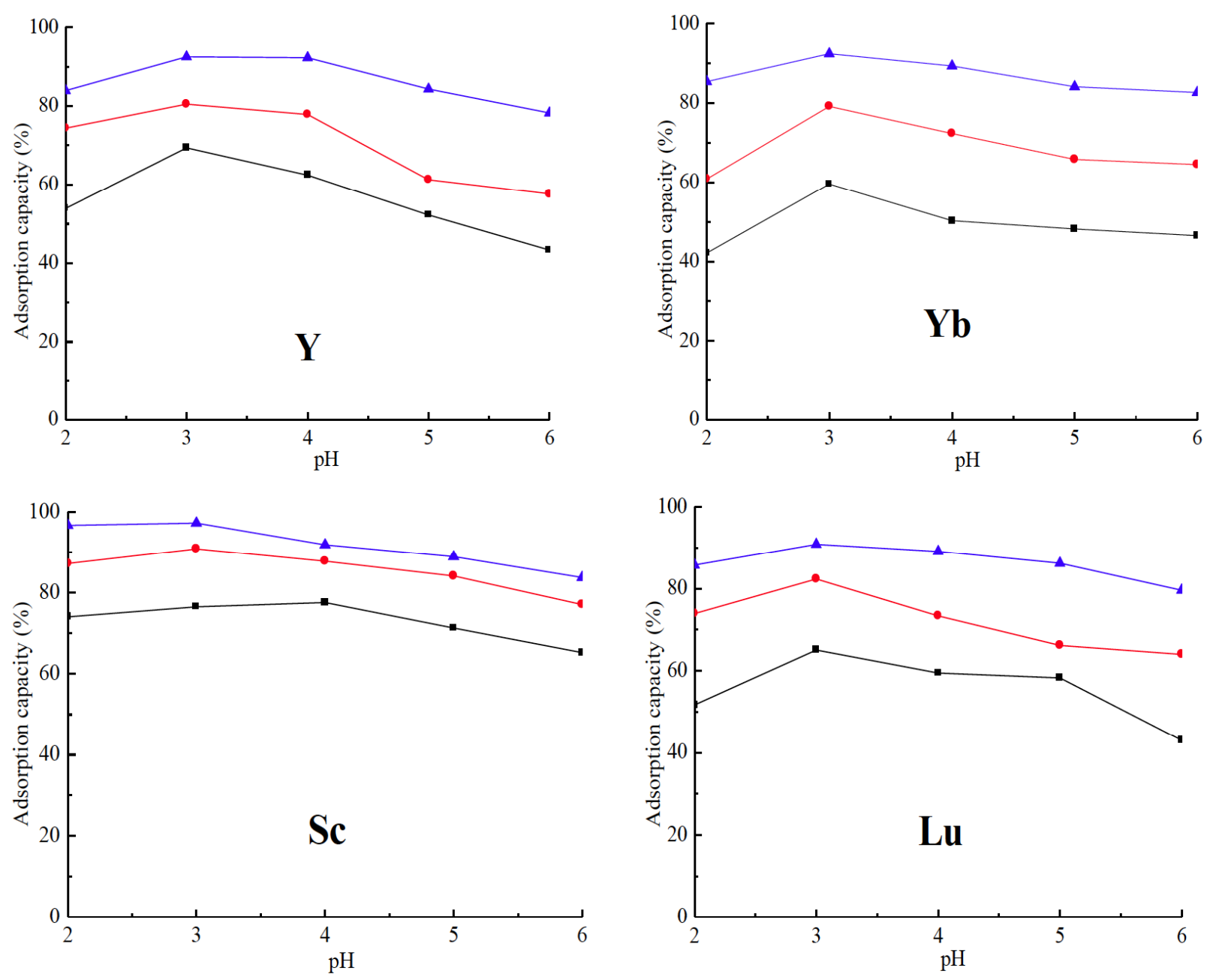
(Figure 3). Continued.

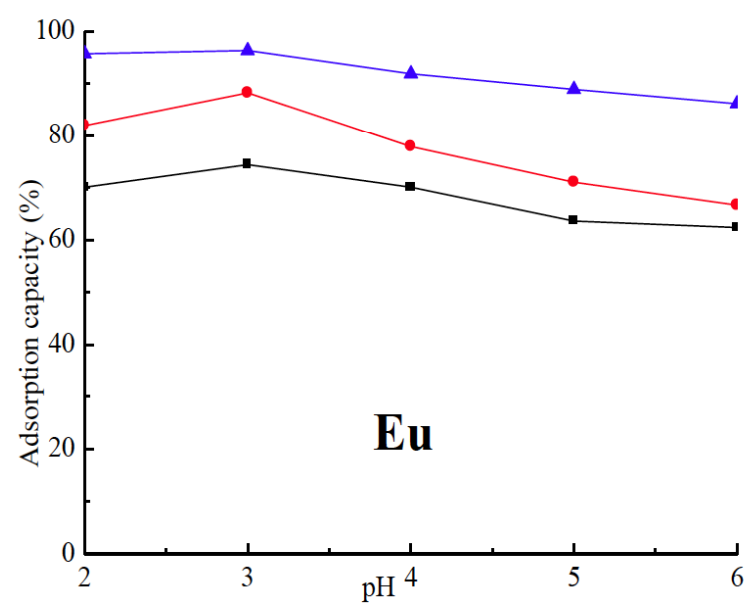

Figure 3: Effect of $\mathrm{pH}$ on the removal of REEs using $\mathrm{ACs}\left(\mathbf{n}: \mathrm{AC}_{0} ; \bullet: A C_{\mathrm{K} 1} ; \mathbf{\Lambda}: \mathrm{AC}_{\mathrm{K} 3}\right)$.

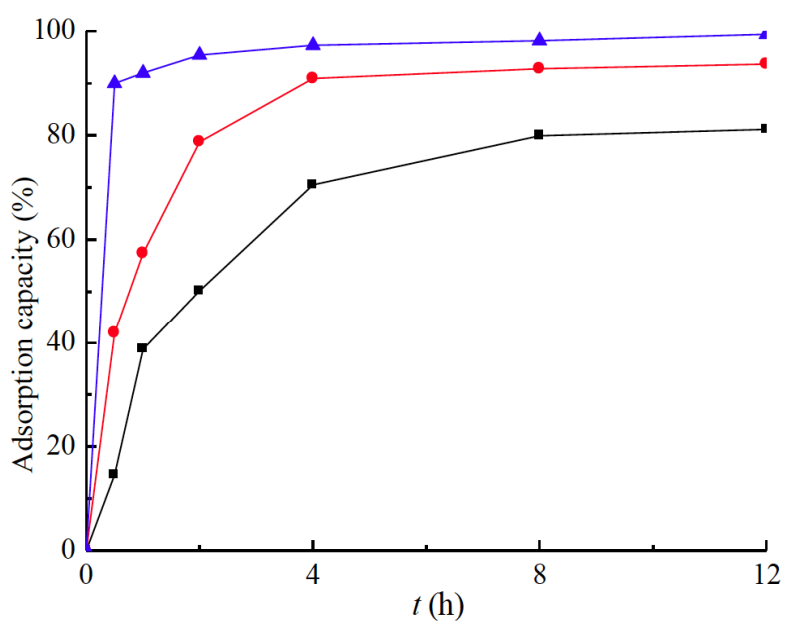

Figure 4: Effect of contact time on the removal of Sc using $\operatorname{ACs}\left(\mathbf{m}: \mathrm{AC}_{0} ; \bullet: \mathrm{AC}_{\mathrm{K} 1} ; \boldsymbol{\Delta}: \mathrm{AC}_{\mathrm{K} 3}\right)$.

\subsection{Adsorption Isotherms}

Adsorption isotherms are commonly used to reflect the performance of adsorbents in adsorption processes. The adsorption data obtained for REEs using ACs were analyzed by Langmuir and Freundlich equations. The correlation coefficient $\left(R^{2}\right)$ of these isotherms for REEs on ACs is shown in Table 2 along with other relevant parameters.

From Table 2, it is found that the adsorption capacity of REEs by $A C_{K 1}$ and $A_{C^{3} 3}$ were larger than that by $A C_{0}$. It indicates that the surface modification by the impregnation of $\mathrm{KMnO}_{4}$ was effective. Adsorption of REEs onto these materials may be occurred by ion exchange between functional groups such as carboxylic or phenolic hydroxyl and metallic ions.

Then, the improvement of the adsorption capacity may be attributable to the creation of the functional

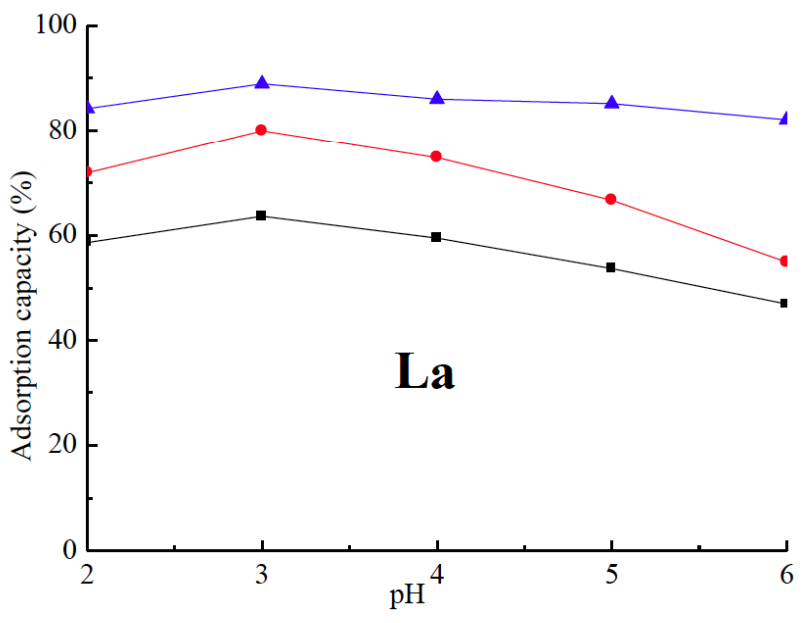

groups (e.g., - $\mathrm{COOH}$ ) by carbon oxidation as well as the formation of the adsorption site by production of $\mathrm{MnO}_{2}$ with the impregnation of $\mathrm{KMnO}_{4}$.

From Table 2, it is also found that $R^{2}$ value for REEs is comparatively large, and favorable adsorption of REEs by ACs was presented. Particularly, $R^{2}$ values in Langmuir isotherm are large for all REEs. This result suggests that the adsorption of REEs on ACs mainly occurred by monolayer reaction. From the nature of the material, multiple binding sites are available, and both physical and chemical adsorptions may occurred in these ACs.

Based on the data, the linear plots of $C_{e} / q_{e}-C_{e}$ were presented for Langmuir, and are shown in Figure 5. It is indicated that favorable adsorption for REEs by the activated carbon is presented.

\subsection{Kinetic Studies}

Kinetic models were tested in this study for the sorption of REEs onto ACs under optimized experimental conditions. The results for rate constant $(k)$ and the amount of adsorbed REEs $\left(q_{e}\right)$ are shown in Table 3 along with the regression coefficients $\left(R^{2}\right)$. From this table, it is found that the pseudo secondorder kinetic model provided more comparable than the pseudo first-order model.

It implies that the adsorption kinetics based on the experimental values is in good agreement with the pseudo second-order kinetic model. It is considered that the rate determining step might be chemical, and that the adsorption process involves the valency forces through sharing electrons between the metal ions and adsorbent. 
Table 2: Coefficient of Langmuir and Freundlich Isotherms for REEs

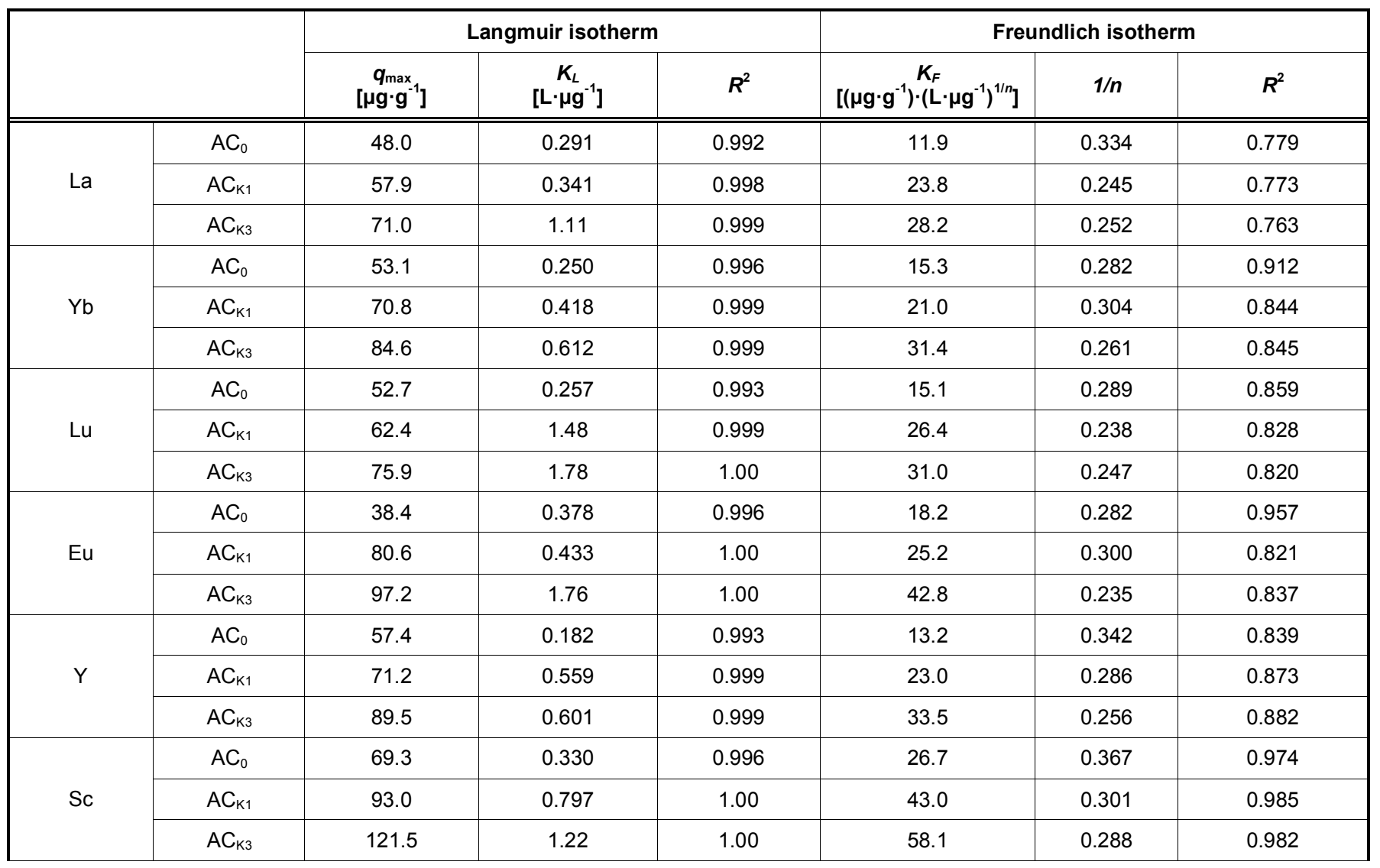
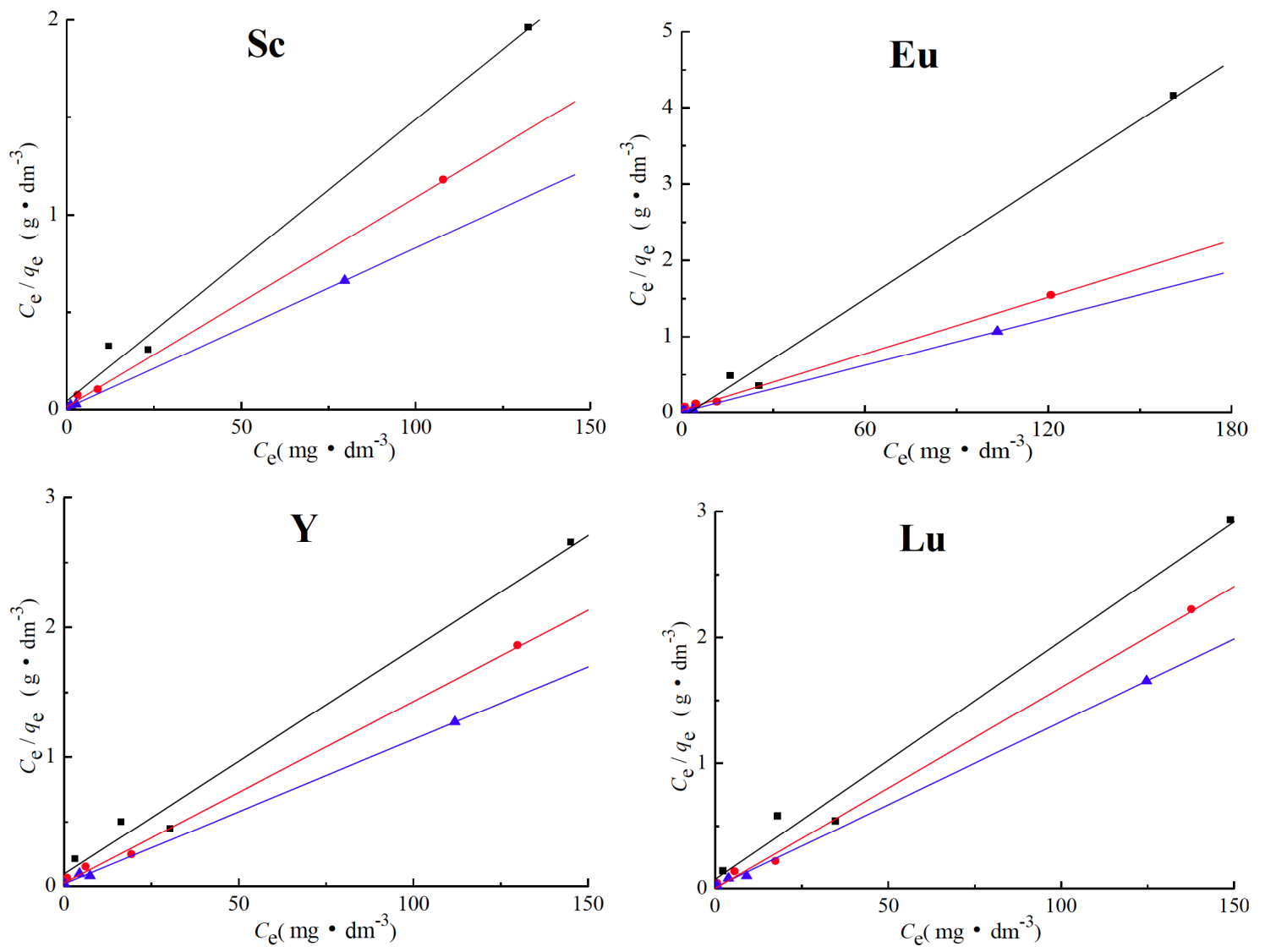
(Figure 5). Continued.
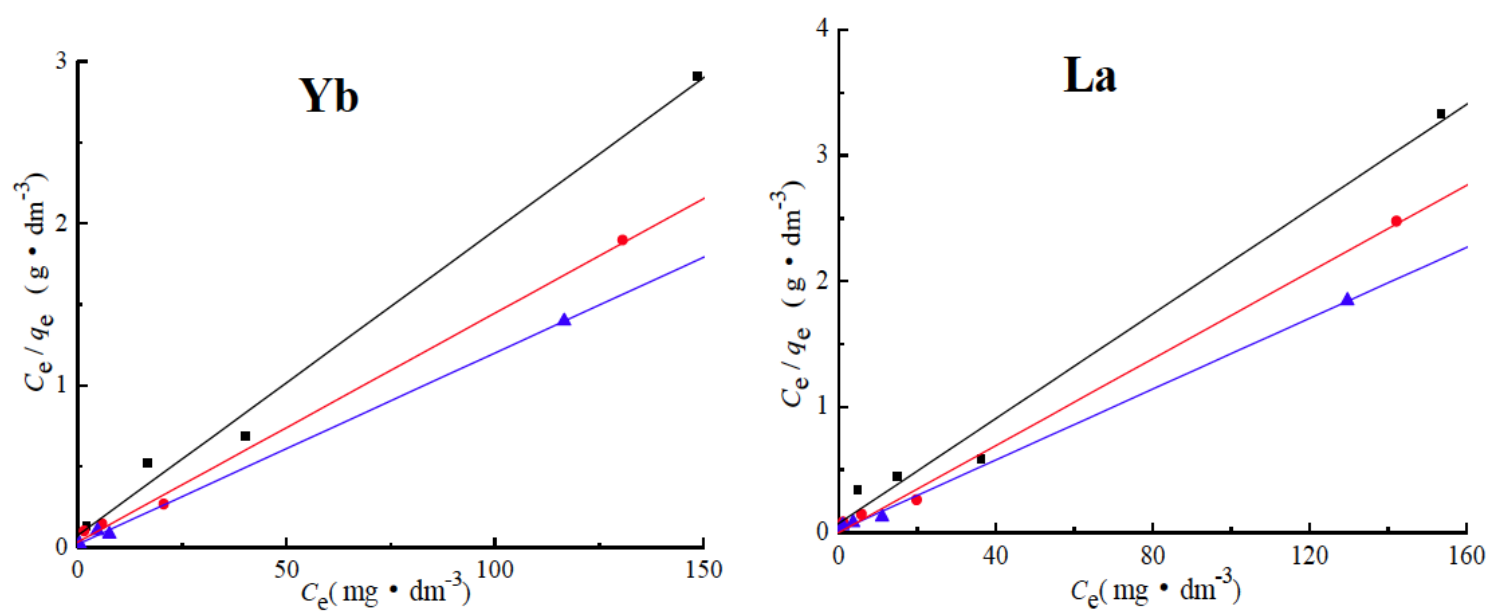

Figure 5: Langmiur isotherm of REEs adsorption onto $A C s\left(\mathbf{m}: A C_{0} ; \bullet: A C_{K 1} ; \Delta: A C_{K 3}\right)$.

Table 3: Kinetic Coefficient for REEs Adsorption on Adsorbents

\begin{tabular}{|c|c|c|c|c|c|c|c|}
\hline & & \multicolumn{3}{|c|}{ pseudo-first-order } & \multicolumn{3}{|c|}{ pseudo-second-order } \\
\hline & & $\begin{array}{c}q_{e} \\
\left(\mu g \cdot g^{-1}\right)\end{array}$ & $\begin{array}{c}k_{1} \\
\left(h^{-1}\right)\end{array}$ & $R^{2}$ & $\begin{array}{c}q_{e} \\
\left(\mu g \cdot g^{-1}\right)\end{array}$ & $\begin{array}{c}k_{2} \\
\left(10^{-2} \cdot g \cdot \mu g^{-1} \cdot h^{-1}\right)\end{array}$ & $R^{2}$ \\
\hline \multirow[t]{2}{*}{ La } & $\mathrm{AC}_{\mathrm{K} 1}$ & 49.7 & 0.401 & 0.980 & 92.9 & 1.39 & 0.999 \\
\hline & $\mathrm{AC}_{\mathrm{K} 3}$ & 69.7 & 0.440 & 0.959 & 99.9 & 1.56 & 0.999 \\
\hline \multirow[t]{2}{*}{$\mathrm{Yb}$} & $\mathrm{AC}_{\mathrm{K} 1}$ & 60.0 & 0.390 & 0.979 & 97.6 & 1.08 & 0.999 \\
\hline & $\mathrm{AC}_{\mathrm{K} 3}$ & 85.0 & 0.428 & 0.959 & 102 & 1.80 & 1.00 \\
\hline \multirow[b]{2}{*}{$\mathrm{Lu}$} & $\mathrm{AC}_{0}$ & 38.4 & 0.337 & 0.954 & 58.8 & 0.236 & 0.964 \\
\hline & $\mathrm{AC}_{\mathrm{k} 1}$ & 50.8 & 0.339 & 0.959 & 95.1 & 1.26 & 0.999 \\
\hline $\mathrm{Eu}$ & $\mathrm{AC}_{\mathrm{K} 3}$ & 82.1 & 0.529 & 0.968 & 104 & 2.41 & 1.00 \\
\hline \multirow{3}{*}{$\mathrm{Y}$} & $\mathrm{AC}_{0}$ & 45.9 & 0.288 & 0.986 & 93.5 & 0.471 & 0.993 \\
\hline & $\mathrm{AC}_{\mathrm{K} 1}$ & 48.0 & 0.440 & 0.954 & 97.8 & 1.41 & 1.00 \\
\hline & $\mathrm{AC}_{\mathrm{K} 3}$ & 79.3 & 0.462 & 0.959 & 103 & 1.63 & 0.999 \\
\hline \multirow{3}{*}{ Sc } & $\mathrm{AC}_{0}$ & 8.48 & 0.261 & 0.957 & 91.3 & 0.942 & 0.993 \\
\hline & $\mathrm{AC}_{\mathrm{K} 1}$ & 51.3 & 0.477 & 0.968 & 98.9 & 1.54 & 0.996 \\
\hline & $\mathrm{AC}_{\mathrm{K} 3}$ & 66.7 & 0.553 & 0.951 & 100 & 1.90 & 1.00 \\
\hline
\end{tabular}

Generally, the adsorption takes place in two steps. The first linear region represents the stage of film diffusion, which is the diffusion of REEs from the bulk solution to the external surface of the ACs. The second region can be attributed to intraparticle diffusion stage due to the rough surface and voids within the ACs. The film diffusion stage is larger than the intraparticle diffusion stage, which is represented by larger slope $\left(k_{p}\right)$. The lower slope for the intraparticle diffusion indicates more gradual process, which is consistent with the parameters of Weber's intraparticle diffusion model [44]. Most of the plots do not pass through the origin, indicating the intraparticle diffusion is not the rate limiting step [45]. The intercept reflects the 
boundary layer effect, that is, the larger the intercept, the greater the contribution of the surface adsorption in the rate controlling steps [46].

\subsection{Regeneration Studies}

From industrial and technological point of view, it is desirable to recover and reuse the adsorbed material. Then, preliminary regeneration experiments were conducted using $\mathrm{AC}_{\mathrm{K} 3}$ after adsorption of $\mathrm{La}(\mathrm{III})$ at $\mathrm{pH}$ 3. In each desorption experiment, $50 \mathrm{mg}$ of the spent adsorbent after adsorption was treated with $50 \mathrm{ml}$ of each desorption agent, and then filtered. La(III) content in the filtrate was determined by ICP-AES. Adsorption and desorption studies have been continued during five cycles by using $\mathrm{HCl}(5 \%$ and $10 \%), \mathrm{HNO}_{3}(5 \%$ and $10 \%$ ) and $\mathrm{NaOH}(5 \%$ and $10 \%)$ at $90^{\circ} \mathrm{C}$ for $4 \mathrm{~h}$ as eluent. The adsorption capacity after desorption using the above leaching agents are shown in Figure 6.

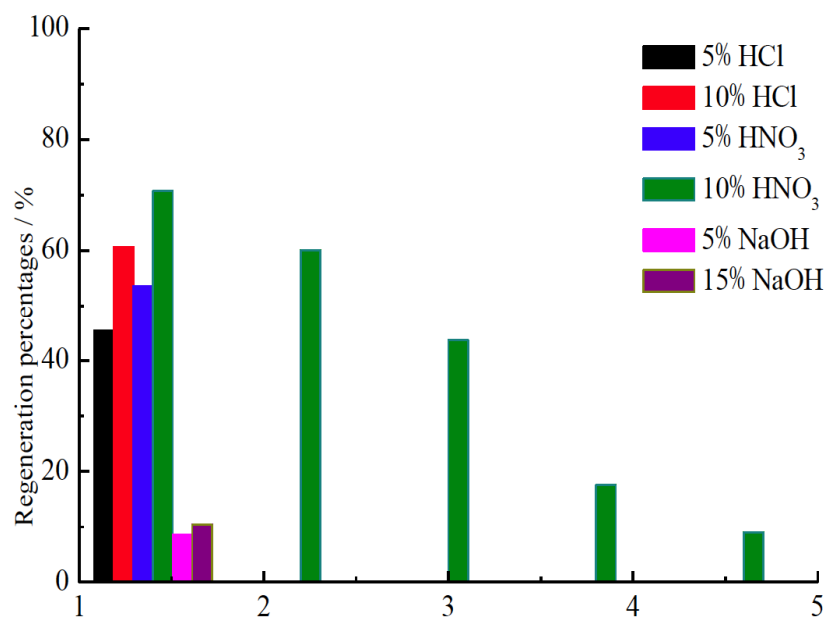

Figure 6: The adsorption capacity after desorption using various leaching agents for La (III).

From this figure, it is found that the desorption rate of La (III) from the adsorbent are dependent upon the nature of the extracting solution, and $10 \% \mathrm{HNO}_{3}$ is more suitable for the desorption agent. ACs still present the high adsorption capacity towards La within 3 cycles.

\section{CONCLUSIONS}

The present study investigated the efficiency of activated carbon modified with $\mathrm{KMnO}_{4}$ as adsorbent for REEs by batch techniques. The following conclusions can be drawn considering the results of this work.

Adsorption capacity of REEs by $\mathrm{AC}_{\mathrm{K} 1}$ or $\mathrm{AC}_{\mathrm{K} 3}$ were larger than that by $\mathrm{AC}_{0}$. It indicates that the surface modification with $\mathrm{KMnO}_{4}$ was effective.
Adsorption of REEs onto these materials can generally be attributed to ion exchange between functional groups such as carboxylic or phenolic hydroxyl and metallic ions.

(2) The adsorption isotherm of REEs by ACs was more suitably described by Langmuir model, and the correlation coefficients were more than 0.99 for all REEs. It suggests that monolayer chemical adsorption of REEs on ACs is more dominant.

(3) The rates of adsorption were conformed to pseudo-second order kinetic model while investigating the adsorption kinetics, and the correlation coefficients were both more than 0.99 for all REEs. This analysis revealed that the rate determining step might be the adsorption processes involved the valency forces through sharing electron between the metallic ions and adsorbents.

(4) Desorption of La (III) from the adsorbent has been found to depend upon the nature of the extracting solution. ACs still present the high adsorption capacity towards La for the adsorption/desorption behavior within 3 cycles by $10 \% \mathrm{HNO}_{3}$.

From this work, it was quantitatively clarified to some extent that ACs could be an efficient adsorbent for REEs. They created new avenues for the treatment of industrial waste waters including pollutants. It is very significant information from the viewpoint of environmental protection.

\section{ACKNOWLEDGEMENTS}

The present work was partially supported by a Grant-in-Aid for Scientific Research (Research Program (C), No. 16K00599) of the Japan Society for the Promotion of Science. This research was also supported by a fund for the promotion of Niigata University KAAB Projects from the Ministry of Education, Culture, Sports, Science and Technology, Japan.

The authors are also grateful to Mr. M. Ohizumi of Office for Environment and Safety in Niigata University, and to Mr. T. Nomoto and Prof. T. Tanaka of Fac. of Eng. in Niigata University for permitting the use of ICPAES and SEM for giving helpful advice in measurement. 


\section{REFERENCES}

[1] Bauer D, Diamond D, Li J, Sandalow D, Telleen P, Wanner B. US Department of Energy Critical Materials Strategy. U.S. Department of Energy Critical Materials Strategy, United States 2010. https://doi.org/10.2172/1000846

[2] Smith YR, Bhattacharyya D, Willhard T, Misra M. Adsorption of aqueous rare earth elements using carbon black derived from recycled tires. Chem Eng J 2016; 296: 102-111. https://doi.org/10.1016/j.cej.2016.03.082

[3] Peng G, Tian G, Liu J, Bao Q, Zang L. Removal of heavy metals from sewage sludge with a combination of bioleaching and electrokinetic remediation technology. Desalination 2011; 271: 100-104. https://doi.org/10.1016/j.desal.2010.12.015

[4] Sag Y, Kutsal T. Determination of the biosorption heats of heavy metal ions on Zoogloea ramigera and Rhizopus arrhizus. Biochem Eng J 2000; 6: 145-151. https://doi.org/10.1016/S1369-703X(00)00083-8

[5] Bahramifar N, Yamini Y. On-line preconcentration of some rare earth elements in water samples using $C$ 18-cartridge modified with I-(2-pyridylazo) 2-naphtol (PAN) prior to simultaneous determination by inductively coupled plasma optical emission spectrometry (ICP-OES). Analytica Chimica Acta 2005; 540: 325-332.

https://doi.org/10.1016/j.aca.2005.03.058

[6] He M, Hu B, Zeng Y, Jiang Z. ICP-MS direct determination of trace amounts of rare earth impurities in various rare earth oxides with only one standard series. J Alloy Compd 2005; 390: 168-174.

https://doi.org/10.1016/j.jallcom.2004.06.107

[7] Yesiller SU, Eroglu AE, Shahwan T. Removal of aqueous rare earth elements (REEs) using nano-iron based materials. $\mathrm{J}$ Ind Eng Chem Res 2013; 19: 898-907. https://doi.org/10.1016/j.jiec.2012.11.005

[8] Davranche M, Pourret O, Gruau G, Dia A. Impact of humate complexation on the adsorption of REE onto $\mathrm{Fe}$ oxyhydroxide. J Colloid Interf Sci 2004; 277: 271-279. https://doi.org/10.1016/j.jcis.2004.04.007

[9] Wan Y, Liu C. The effect of humic acid on the adsorption of REEs on kaolin. Colloids and Surfaces A: Physicochem. Eng Aspects 2006; 290: 112-117.

https://doi.org/10.1016/j.colsurfa.2006.05.010

[10] Sanematsu K, Kon Y, Imai A. Influence of phosphate on mobility and adsorption of REEs during weathering of granites in Thailand. J Asian Earth Sci 2015; 111: 14-30. https://doi.org/10.1016/j.jseaes.2015.05.018

[11] Ding SM, Liang T, Zhang CS, Huang ZC, Xie YN, Chen TB. Fractionation Mechanisms of Rare Earth Elements (REEs) in Hydroponic Wheat: An Application for Metal Accumulation by Plants. Environ Sci Technol 2006; 40: 2686-2691.

https://doi.org/10.1021/es052091b

[12] Suat U, Murat E, Turgay T, Selhan K. Removal of lead (II) and nickel (II) ions from aqueous solution using activated carbon prepared from rapeseed oil cake by $\mathrm{Na}_{2} \mathrm{CO}_{3}$ activation. Clean Tech Environ Policy 2015; 17: 747-756. https://doi.org/10.1007/s10098-014-0830-8

[13] Peric J, Trgo M, Medvidovic NV. Removal of zinc, copper and lead by natural zeolite-a comparison of adsorption isotherms. Water Research 2004; 38: 1893-1899.

https://doi.org/10.1016/j.watres.2003.12.035

[14] Mobasherpour I, Salahi E, Ebrahimi M. Removal of divalent nickel cations from aqueous solution by multi-walled carbon nano tubes: equilibrium and kinetic processes. Res Chem Intermed 2012; 38: 2205-2222.

https://doi.org/10.1007/s11164-012-0537-6

[15] Wang JL, Chen C. Biosorbents for heavy metals removal and their future. Biotechnol Adv 2009; 27: 195-226.

https://doi.org/10.1016/j.biotechadv.2008.11.002
[16] Haider S, Bukhari N, Park SY, Iqbal Y, Masry WA. Adsorption of bromo-phenol blue from an aqueous solution onto thermally modified granular charcoal. Chem Eng Res Des 2011; 89: 23-28.

https://doi.org/10.1016/j.cherd.2010.04.022

[17] Sun YB, Yang ST, Sheng GD, Guo ZQ, Wang XK. The removal of $\mathrm{U}(\mathrm{VI})$ from aqueous solution by oxidized multiwalled carbon nanotubes. J Environ Radioact 2012; 105: 40-47. https://doi.org/10.1016/j.jenvrad.2011.10.009

[18] Tuzun I, Bayramoglu G, Yalcin E, Basaran G, Celik G, Anca MY. Equilibrium and kinetic studies on biosorption of $\mathrm{Hg}(\mathrm{II})$, $\mathrm{Cd}(\mathrm{II})$ and $\mathrm{Pb}(\mathrm{II})$ ions onto microalgae Chlamydomonas reinhardtii. J Environ Manage 2005; 77: 85-92. https://doi.org/10.1016/j.jenvman.2005.01.028

[19] Ricordel S, Taha S, Cisse I, Dorange G. Heavy metals removal by adsorption onto peanut husks carbon: characterization, kinetic study and modeling. Sep Purif Technol 2001; 24: 389-401.

https://doi.org/10.1016/S1383-5866(01)00139-3

[20] Dilek D, Andrzej WT, Ulker B. Kinetics and thermodynamics of hexavalent chromium adsorption onto activated carbon derived from acrylonitrile-divinylbenzene copolymer. Chem Eng J 2012; 187: 193-202.

https://doi.org/10.1016/j.cej.2012.01.120

[21] Kobya M, Demirbas E, Senturk E, Lnce M. Adsorption of heavy metal ions from aqueous solutions by activated carbon prepared from apricot stone. Bioresour Technol 2005; 96: 1518-1521.

https://doi.org/10.1016/j.biortech.2004.12.005

[22] Li YH, Di Z, Ding J, Wu D, Luan Z, Zhu Y. Adsorption thermodynamics, kinetic and desorption studies of $\mathrm{Pb}^{2+}$ on carbon nanotubes. Water Res 2005; 39: 605-609. https://doi.org/10.1016/j.watres.2004.11.004

[23] Rao GP, Lu C, Su F. Sorption of divalent metal ions from aqueous solution by carbon nanotubes: a review. Sep Purif Technol 2007; 58: 224-231. https://doi.org/10.1016/j.seppur.2006.12.006

[24] Li YH, Wang SG, Luan ZK, Ding J, Xu CL. Adsorption of cadmium(II) from aqueous solution by surface oxidized carbon nanotubes. Carbon 2003; 41: 1057-1062 https://doi.org/10.1016/S0008-6223(02)00440-2

[25] Shan XM, Zhu SQ, Zhang WH. Effect of surface modification of activated carbon on its adsorption capacity for $\mathrm{NH}_{3}$. J China Univ Mining Technol 2008; 18: 0261-0265. https://doi.org/10.1016/S1006-1266(08)60055-3

[26] Rasheed A, Howe JY, Dadmun MD, Britt PF. The efficiency of the oxidation of carbon nanofibers with various oxidizing agents. Carbon 2007; 45: 1072-1080. https://doi.org/10.1016/j.carbon.2006.12.010

[27] Lu C, Chiu H. Chemical modification of multiwalled carbon nanotubes for sorption of $\mathrm{Zn}^{2+}$ from aqueous solution. Chem Eng J 2008; 139(3): 462-468.

https://doi.org/10.1016/j.cej.2007.08.013

[28] Mourão PAM, Laginhas C, Custódio F, Nabais JMV, Carrott PJM, Ribeiro Carrott MML. Influence of oxidation process on the adsorption capacity of activated carbons from lignocellulosic precursors. Fuel Process Ttechnol 2011; 92(2): 241-246.

https://doi.org/10.1016/j.fuproc.2010.04.013

[29] Daifullah AAM, Yakout SM, Elreefy SA. Adsorption of fluoride in aqueous solutions using $\mathrm{KMnO}_{4}^{-}$modified activated carbon derived from steam pyrolysis of rice straw. J Hazard Mater 2007; 147: 633-643.

https://doi.org/10.1016/j.jhazmat.2007.01.062

[30] Fual G, Hakan Y, Giray T. Determination of kinetic and equilibrium parameters of the batch adsorption of $\mathrm{Mn}$ (II), $\mathrm{Co}(\mathrm{II}), \mathrm{Ni}(\mathrm{II})$ and $\mathrm{Cu}(\mathrm{II})$ from aqueous solution by black carrot (Daucus carota L.) residues. J Hazard Mater 2008; 153: 1275-1287.

https://doi.org/10.1016/j.jhazmat.2007.09.087 
[31] Muhammad A, Shafaqat A, Muhammad R, Muhammad Z, Muhammad I, Farhat A, et al. Mechanisms of siliconmediated alleviation of heavy metal toxicity in plants: a review. Ecotoxicol Environ Saf 2015; 119: 186-197. https://doi.org/10.1016/j.ecoenv.2015.05.011

[32] Dhaouadi A, Monser L, Adhoum N. Removal of rotenone insecticide by adsorption onto chemically modified activated carbons. J Hazard Mater 2010; 181: 692-699. https://doi.org/10.1016/j.jhazmat.2010.05.068

[33] Sarin V, Pant KK. Removal of chromium from industrial waste by using eucalyptus bark. Bioresour Technol 2006; 97 : 15-20. https://doi.org/10.1016/j.biortech.2005.02.010

[34] Duranoğlu D, Trochimczuk AW, Beker U. Kinetics and thermodynamics of hexavalent chromium adsorption onto activated carbon derived from acrylonitrile-divinylbenzene copolymer. Chem Eng J 2012; 187: 193-202. https://doi.org/10.1016/j.cej.2012.01.120

[35] Hall KR, Eagleton LC, Acrivos A, Vermeulen T. Pore and solid-diffusion kinetics in fixed-bed adsorption under constant-pattern conditions. Ind Eng Chem Res 1966; 5: 213-223. https://doi.org/10.1021/i160018a011

[36] Rahmati MM, Rabbani P, Abdolali A, Keshtkar AR. Kinetics and equilibrium studies on biosorption of cadmium, lead, and nickel ions from aqueous solutions by intact and chemically modified brown algae. J Hazard Mater 2011; 185: 401-407. https://doi.org/10.1016/j.jhazmat.2010.09.047

[37] Pillai SS, Mullassery MD, Fernandez NB, Girija N, Geetha P, Koshy M. Biosorption of $\mathrm{Cr}(\mathrm{VI})$ from aqueous solution by chemically modified potato starch: Equilibrium and kinetic studies. Ecotox Environ Safe 2013; 92: 199-205. https://doi.org/10.1016/j.ecoenv.2013.01.020

[38] Zhu JZ, Yang J, Deng BL. Ethylenediamine modified Activated Carbon for Aqueous Lead Adsorption, Environ. Chem Lett 2010; 8: 277-282. https://doi.org/10.1007/s10311-009-0217-y

[39] Chingombe P, Saha B, Wakeman RJ. Surface modification and characterisation of a coal-based activated carbon. Carbon 2005; 43: 3132-3143. https://doi.org/10.1016/j.carbon.2005.06.021
[40] Dolatyari L, Yaftian MR, Rostamnia S. Adsorption characteristics of $\mathrm{Eu}(\mathrm{III})$ and Th(IV) ions onto modified mesoporous silica SBA-15 materials. J Taiwan Inst Chem Engrs 2016; 60: 174-184.

https://doi.org/10.1016/j.jtice.2015.11.004

[41] Liu $\mathrm{YH}$, Li Q, Cao XH, Wang $Y Q$, Jiang $\mathrm{XH}$, Li M, et al. Removal of uranium(VI) from aqueous solutions by CMK-3 and its polymer composite. Appl Surf Sci 2013; 285: 258266.

https://doi.org/10.1016/j.apsusc.2013.08.048

[42] Gerente C, Lee VKC, Cloirec PL, Mckay G. Application of chitosan for the removal of metals from wastewaters by adsorption-Mechanisms and models review. Crit Rev Env Sci Tec 2007; 37: 41-127. https://doi.org/10.1080/10643380600729089

[43] Abbasizadeh S, Keshtkar AR, Mousavian MA. Preparation of a novel electrospun polyvinyl alcohol/titanium oxide nanofiber adsorbent modified with mercapto groups for uranium(VI) and thorium(IV) removal from aqueous solution. Chem Eng $J$ 2013; 220: 161-171.

https://doi.org/10.1016/j.cej.2013.01.029

[44] Smith YR, Bhattacharyya D, Willhard T, Misra M. Adsorption of aqueous rare earth elements using carbon black derived from recycled tires. Chem Eng J 2016; 296: 102-111. https://doi.org/10.1016/j.cej.2016.03.082

[45] Chen L, Bai B. Equilibrium, kinetic, thermodynamic, and in situ regeneration studies about methylene blue adsorption by the raspberry-like $\mathrm{TiO}_{2}$ yeast microspheres. Ind. Eng Chem Res 2013; 52: 15568-15577. https://doi.org/10.1021/ie4020364

[46] Fu JW, Chen ZH, Wang MH, Liu SJ, Zhang JH, Zhang JN, et al. Adsorption of methylene blue by a high-efficiency adsorbent (polydopamine microspheres): kinetics, isotherm, thermodynamics and mechanism analysis. Chem Eng $J$ 2015; 259(1): 53-61 https://doi.org/10.1016/i.cej.2014.07.101

DOI: https://doi.org/10.6000/1929-5030.2017.06.02.1

(C) 2017 Kano et al.; Licensee Lifescience Global.

This is an open access article licensed under the terms of the Creative Commons Attribution Non-Commercial License (http://creativecommons.org/licenses/by-nc/3.0/) which permits unrestricted, non-commercial use, distribution and reproduction in any medium, provided the work is properly cited. 